\title{
Development of Sandwich Composites for Building Construction with Locally Available Materials
}

\author{
Faris Matalkah, Harsha Bharadwaj, Parviz Soroushian, Wenda Wu, Areej \\ Almalkawi, Anagi M. Balachandra, Amirpasha Peyvandi
}

\begin{abstract}
\end{abstract}
A sandwich composite comprising ferrocement skins was developed as the primary structural module for building construction with indigenous materials. The indigenous reinforcement systems selected for use in ferrocement skins were jute burlap and chicken mesh (flexible galvanized steel wire). These reinforcement systems were characterized through performance of tension tests. The tensile strength, stiffness and ductility of jute burlaps were found to compare favorably with those of chicken mesh which is a viable reinforcement for use in ferrocement. Tension tests on ferrocement sheets indicated that indigenous reinforcement ratios above a threshold level could induce multiple cracking and strain-hardening behavior, producing a desired balance of tensile strength and ductility. The tensile strength of indigenous ferrocements with jute burlap reinforcement exceeded the theoretically predicted values, which could be attributed to the favorable interactions of the burlap reinforcement with the inorganic matrix, and the strengthening effects of hydrates precipitating within the yarn voids in burlap. Experiments were conducted to determine the bond strength and the required development length of the indigenous reinforcement in cementitious matrix. Indigenous sandwich composites comprising ferrocement skins with jute burlap reinforcement and an aerated concrete core made of lime-gypsum matrix and saponin foaming agent were fabricated and subjected to flexure testing. The sandwich composite provided relatively high flexural strengths; the flexural failure modes indicated that the relatively dense aerated concrete core makes important contributions to the flexural performance of the sandwich composite.

Keywords: indigenous materials; building construction; sandwich composites; structural performance 
2 The use of locally available (indigenous) materials in construction yields economic and

3 sustainability benefits by reducing the transportation costs and the associated energy use and

4 carbon emissions. Building systems designed to make maximum use of indigenous materials

5 should still meet requirements relevant to structural safety, quality of life, energy-efficiency,

6 economy, fire resistance and durability $[1,2]$.

7 Modern buildings are generally constructed with materials such as Portland cement concrete,

8 steel, timber, pre-fabricated gypsum panels, masonry units, polymer composites, and insulating

9 foams [3-7]. Some indigenous materials used for building construction include adobe, rammed

10 earth, cob, stabilized soil, stone, brick, concrete block, lime, gypsum, natural pozzolans, biomass

11 ash, vegetable fibers (and their fabrics/ropes), bamboo and tree trunks/stems/leaves [8-17]. These

12 indigenous construction materials are commonly used in the context of traditional building

13 systems which provide basic shelter under regularly encountered load and environmental effects

14 at minimum cost. Their inability to withstand extreme events (e.g., earthquakes and storms),

15 however, has led to a significant disparity in death tolls caused by natural disasters in developing

16 nations where the use of indigenous construction materials is common versus those in developed

17 nations where modern building materials and systems are prevalent [18].

18 In this work, an approach is proposed for scalable and reconfigurable construction of sustainable,

19 energy-efficient, and economically viable building systems using indigenous materials and

20 locally available resources. This approach makes synergistic use of the following materials and

21 principles:

22 - Use of diverse locally available plant fibers as reinforcing fabric to replace wire mesh in

23 ferrocement $[15,19]$ 
- Development of sandwich composites comprising exterior layers (skins) of ferrocement made with indigenous binders and fabrics, and

- Interior layer (core) of aerated concrete made with indigenous binders and indigenous foaming agents extracted from abundant plants [20,21]

It should be noted that the reliance on less processed indigenous materials would raise the variability of material properties. Careful selection of quality control methods that can be implemented considering the constraints of indigenous construction would be important for reliable production of indigenous building materials and systems.

Fabrics made of natural (e.g., jute, sisal, kenaf) fibers are readily available in different geographic areas [22-24]. Hexagonal wire netting (chicken mesh) is also an option across the world. These indigenous reinforcement systems suit production of ferrocement, a thin-sheet reinforced cement product with a distinct balance of qualities that can be processed, using unskilled labor, into structurally efficient configurations [25]. Jute fabric (burlap) was selected for development of the indigenous building modules in this study. The fabric (burlap) as well as chicken mesh is considered in this work as indigenous reinforcement for production of ferrocement.

Ferrocement is a thin-sheet cement product where fabrics comprising relatively small-diameter wires with high specific surface area are used as reinforcement in a cementitious mortar matrix. The reinforcement volume fraction in ferrocement is relatively high when compared with that in conventional reinforced concrete $[26,27]$. The high reinforcement ratio and specific surface area, and the improved bonding via mechanical anchorage of the 2D fabric (compared to 1D rebar) reinforcement induce multiple cracking in ferrocement under tensile and flexural loading. This phenomenon enables redistribution of internal forces from critically stressed areas, and enhances 
1 the ductility and energy absorption capacity of ferrocement structures. The reinforcement volume

2 fraction $\left(\mathrm{V}_{\mathrm{r}}\right)$ is an important attribute of ferrocement, which depends upon (Figure 1) the number

3 of fabric reinforcement layers $(\mathrm{N})$, diameter of the fabric wires/yarns $\left(\mathrm{d}_{\mathrm{w}}\right)$, center-to-center

4 spacing of wires/yarns in longitudinal and transverse directions ( $\mathrm{D}_{\mathrm{L}}$ and $\mathrm{D}_{\mathrm{T}}$, respectively), and

5 the total thickness of ferrocement (h) [26]:

$6 \quad V_{r}=\frac{N \cdot \pi \cdot d_{W}^{2}}{4 h} \cdot\left(\frac{1}{D_{L}}+\frac{1}{D_{T}}\right)$

$<$ Figure 1 >

8 In tensile loading of ferrocement (which is key to the sandwich composite performance), the

9 cementitious matrix contributes to the tensile load-carrying capacity prior to cracking. Upon

10 cracking, however, the tensile force is largely transferred to the reinforcing fabric. Depending on

11 the reinforcement ratio, specific surface area and bond strength, failure could either occur at the

12 first crack formed, or after formation of multiple cracks.

13 A minimum fabric reinforcement volume fraction $\left(\mathrm{V}_{\mathrm{r}}\right)_{\min }$ is required for preventing brittle failure

14 upon cracking (i.e., transfer of the composite tensile force to the reinforcing fabric at the first 15 crack) [26]:

$16\left(V_{r}\right)_{\min }=\frac{1}{\frac{\sigma_{r u}}{\sigma_{m u}}+1-n}$

17 Where, $\sigma_{\mathrm{ru}}$ and $\sigma_{\mathrm{mu}}$ are the reinforcement and matrix tensile strengths, respectively, and $\mathrm{n}$ is the 18 modular ratio of the reinforcing fabric to cementitious matrix.

19 With adequate area of fabric reinforcement in the direction of loading and reinforcement-to20 matrix bond strength, ferrocement experiences multiple cracking. The average spacing between 21 multiple cracks ( $\mathrm{L}_{\mathrm{avg}}$ ) can be calculated as follows [26]: 
$1 \quad L_{a v g}=\frac{\sigma_{m u} \cdot \gamma}{\tau \cdot S_{r l}}$

2 Where, $\sigma_{\mathrm{mu}}$ is the matrix tensile strength, $\mathrm{Y}$ is a constant coefficient ranging from 1 to 2 (usually

3 taken as 1.5), $\tau$ is bond strength, and $\mathrm{S}_{\mathrm{rl}}$ is the specific surface area of the reinforcing fabric in the

$4 \quad$ longitudinal direction.

\section{2. Experimental program}

\section{$6 \quad 2.1$ Materials and methods}

7 After preliminary screening of several natural fabrics, two jute fabrics (burlaps) as well as a 8 commonly available chicken mesh (Figure 2) were selected for use in this investigation. The

9 chicken mesh was made of wires with $1.5 \mathrm{~mm}$ diameter; the hexagonal mesh openings had 10 smallest and largest dimension of 2 and $4 \mathrm{~mm}$, respectively. The 'Jute 1' and 'Jute 2' burlaps

11 shown in Figure 2 had square openings of 1.5 and $3 \mathrm{~mm}$, respectively; the corresponding yarn

12 diameters were 1.2 and $0.9 \mathrm{~mm}$, respectively. The 3-mm opening of the 'Jute 2' natural fabric

13 probably makes it more suitable for use as reinforcement in ferrocement. This is because a larger

14 opening prevents the burlap from filtering larger (sand) particles of the mortar used as matrix in

15 ferrocement. In the 'Jute 1' burlap, yarns in perpendicular directions were adhered at their 16 junctures; the 'Jute 2' burlap, on the other hand, comprised woven yarns (which were not 17 adhered together).

19 The indigenous reinforcement systems selected for use in ferrocement were characterized by 20 subjecting them to tension tests. The chicken mesh is not isotropic; tension tests were thus

21 performed in two perpendicular directions. The specimen dimensions were chosen to include a 22 minimum number of hexagonal units of chicken mesh [26]. The tension test specimens were 285 
21 The specimens were kept inside molds under wet burlap for 24 hours. They were then demolded 22 and cured in lime-saturated water for 3 days. Subsequently, they were stored at $50 \%$ relative 23 humidity and room temperature until the test age of 10 days. 
1 Three replicated specimens were used for all tests, and the mean values are reported under test

2 results.

\subsection{Development of indigenous aerated concrete}

4 Aerated concrete constitutes the lightweight core of the sandwich composite used in this

5 investigation. Aerated concrete comprises a 'cementitious' matrix within which air bubbles are

6 introduced (as replacement for aggregates in normal concrete) using a foaming agent. Aerated

7 concrete comprises foams that were formed and stabilized in the mixing water of concrete using

8 a surfactant (surface active agent, which lowers the surface tension of water). Saponins are

9 natural surfactants found abundantly in various plant species. Saponin molecules are composed

10 of a hydrophobic steroid or triterpenoid group, and one or several hydrophilic oligosaccharide

11 chains attached to this group. Saponins are used in cosmetic, food and pharmaceutical products

12 due to their excellent ability to stabilize emulsions and foams, and to solubilize bulky

13 hydrophobic molecules [29]. The saponin molecule can be extracted from the residues of sisal

14 defibering. It has been used in formulation of detergents [20]. Lime/gypsum mortar with saponin

15 foaming agent was developed as aerated concrete. Type I Portland cement and hydrated lime

16 were used. Saponin and calcium sulfate hemi-hydrate were purchased from Sigma Aldrich. The

17 mix design presented in Table 1 . Was identified after preliminary trials.

$<$ Table 1>

19 Foam was generated in water by adding the foaming agent to half of the mixing water, followed

20 by high-speed mixing of the solution. Mixing was continued until all water assumed the 21 appearance of foam. The remained of mixing water was then added, and mixing was continued 22 until a homogeneous aerated concrete was achieved. 
1 The aerated concrete was molded into $50 \mathrm{~mm}$ cube specimens, which were kept under wet burlap

2 for 3 days, and then demolded and stored at 50\% relative humidity and room temperature until

3 the test age of 7 days. The 7-day compressive strength and density of aerated concrete mixtures

4 are presented in Table 2.

5 Stability of the foam structure during curing is also a key requirement in development of aerated

6 concrete. The 7-day compressive strength of this aerated concrete formulation is comparable

7 with those reported in the literature [30].

$<$ Table 2>

\section{$9 \quad 2.3$ Development of sandwich composites}

10

11

12

A sandwich composite was prepared (Figure 4) with $20 \mathrm{~mm}$ skin thickness incorporating two layers of the 'Jute 2' burlap reinforcement, and $80 \mathrm{~mm}$ of aerated concrete core. This specimen had a total height of $120 \mathrm{~mm}$, with length and width of $285 \mathrm{~mm}$ and $110 \mathrm{~mm}$, respectively. The specimen was prepared by sequential casting of the lower skin, the aerated concrete core, and the upper skin inside a mold. This specimen was prepared for testing in flexure.

$<$ Figure 4>

\section{Experimental results and discussion}

\subsection{Characterization of indigenous reinforcement systems}

Typical tensile load-deformation curve for the jute fiber yarns is presented in Figure 5. Tensile deformation initiates with a low-modulus behavior which could, at least partly, be attributed to the realignment and tightening of fibers within the yarn at the early stages of tensioning. Beyond this state, yarns behave almost linearly up to the peak load where they exhibit yielding prior to rupture. The average values of tensile strength, maximum strain at rupture and elastic modulus 
1 (beyond the initial state of low-modulus deformation) are summarized in Table 3. Yarns are

2 assemblies of natural fibers; they enable practical use of natural fibers at practical scales. Similar

3 to wood, the bulk mechanical properties of yarns are a fraction of the corresponding fiber

4 properties [31]. The tensile strengths and elastic moduli measured here are about $20 \%$ of the

5 corresponding fiber properties. The strains at failure of jute yarns are about 4 times those of

6 individual fibers. Since natural fiber yarns are assemblies of individual fibers, their density tends

7 to be lower than that of their constituent fibers. The jute yarn used in this investigation had a

8 density of about $0.9 \mathrm{gr} / \mathrm{cm}^{3}$ compare to $1.4 \mathrm{gr} / \mathrm{cm}^{3}$ for individual jute fibers [31].

$<$ Figure 5>

The natural fiber yarn properties are below those provided by the steels used in ferrocement; the yield strengths of these steels, for example, are about 4 times the tensile strength of jute fiber yarns considered here. Fabrics made with natural fiber yarns, however, provide a closer yarn spacing when compared with the spacing of steel wires meshes (e.g., chicken mesh) used in ferrocement. The orientations of yarns in natural fabric are also more favorable than those in hexagonal steel wire (chicken) mesh. The higher concentration and the favorable orientation of natural fiber yarns can feasibly compensate for the lower mechanical properties of these yarns versus steel wires. Hence, natural fabrics could potentially provide bulk mechanical properties which are competitive against those of the steel wire mesh reinforcement used in ferrocement.

$<$ Table 3>

Failure of chicken mesh involved significant realignment of wires in the hexagonal units of the mesh. With the proper end grips developed in the project, failure of burlaps occurred away from the end grips near the mid-length of specimens. Typical tensile load-deformation curves for chicken mesh, 'Jute 1' burlap and 'Jute 2' burlap are presented in Figures 6, 7 and 8, 
1 respectively. The burlaps exhibit strain-hardening behavior marked by initial deformations at low

2 modulus followed by a rise in modulus. As was the case with individual yarns, the initial low-

3 modulus behavior can be attributed partly to the realignment and tightening of the fibers in yarns

4 under tension. The peak load provided by the 'Jute 1' burlap is comparable to (slightly higher

5 than) that of chicken mesh. 'Jute 2' with a lower solid concentration (larger yarn spacing)

6 provides a peak load that is about one-third that of chicken mesh. The mean values of tensile

7 strength, strain at failure and elastic modulus of the two burlaps and the chicken mesh are

8 presented in Table 4. These results are indicative of the competitive position of the two jute

9 burlaps versus the steel wire chicken mesh. The relatively high strain at failure of chicken mesh

10 can be largely attributed to the significant realignment under tension of the steel wires configured

11 into hexagonal units. It is worth mentioning that confinement in the cementitious matrix of

12 ferrocement would reduce some of the realignments observed in tension testing of fabrics. This

13 would influence the behavior of fabrics in ferrocement versus their behavior when tested alone

14 (without the confinement of the cementitious matrix).

$<$ Figure 6>

$<$ Figure 7>

$<$ Figure $8>$

$<$ Table 4>

\subsection{Characterization of ferrocement with indigenous reinforcement}

Figure 9 presents typical tensile load-deflection and stress-strain curves for the 20 -mm thick ferrocement test specimens with two layers of chicken mesh reinforcement. These specimens did 
1 not exhibit multiple cracking; the width of the first crack grew with increasing deformation on

2 the descending branch of the load-deflection curve. The peak tensile force of the specimen with

3 two layers of chicken mesh was about 1,900 N. This is very close to twice the 'yield force' of a

4 chicken mesh specimen of similar width. It should be noted that the chicken mesh test specimen

5 exhibited a strain-hardening behavior where force increased above the yield level with increasing

6 deformation. This could be attributed to the realignment of wires in chicken mesh along the

7 direction of tensile loading, which could not happen in the confined condition within matrix in

8 ferrocement. In short, the chicken mesh reinforcement in ferrocement determined the peak

9 tensile load-carrying capacity of ferrocement, which was equal to the yield force of chicken

10 mesh times the number of reinforcing mesh layers.

$<$ Figure 9>

12 Ferrocement specimens with $20 \mathrm{~mm}$ thickness and 2 layers of reinforcing fabric did not exhibit

13 multiple cracking irrespective of the fabric type (chicken mesh, 'Jute 1' or 'Jute 2'). Table 5

14 shows calculation of the reinforcement volume fraction for $20 \mathrm{~mm}$ thick ferrocement sheets with

151 and 2 layers of reinforcement. With steel mesh, the reinforcement ratios of 0.0067 and 0.0134

16 used here are relatively low when compared with typical ferrocement reinforcement ratios [26].

17 It is thus not surprising that these ferrocement specimens did not exhibit multiple cracking. In the

18 case of natural fabric, reinforcement ratios are higher than those for chicken mesh. One should,

19 however, consider that natural fiber (jute) yarns are relatively loose assemblies of fibers.

20 Therefore, the yarns which constitute the fabric, unlike steel wires in chicken mesh, incorporate a

21 high degree of porosity. The actual solid reinforcement volume fraction is thus lower than the 22 fabric volume fraction. 
1 One can interpret the minimum reinforcement ratio introduced earlier as the threshold above

2 which a trend towards multiple cracking would be observed. In order to evaluate the

3 reinforcement ratios presented in Table 5, approximate calculations of the minimum

4 reinforcement ratios $\left(\mathrm{V}_{\mathrm{r}}\right)_{\min }$ for different reinforcement systems were performed using the

5 equation presented earlier. The results, summarized in Table 6, indicate that minimum

6 reinforcement ratios are about three times those obtained with two layers of different fabric types

7 in $20 \mathrm{~mm}$ thick ferrocement sheets. In order to reach the minimum reinforcement ratios, the

8 thickness of ferrocement specimens was reduced to half (from $20 \mathrm{~mm}$ to $10 \mathrm{~mm}$ ), and the

9 number of layers was increased by $50 \%$ (from 2 to 3 layers). For comparison purposes, $10 \mathrm{~mm}$

10 thick specimens with 2 layers of fabric were also tested. Table 7 presents the reinforcement

11 volume fractions in $10 \mathrm{~mm}$ thick ferrocement specimens with 2 and 3 layers of different

12 reinforcing fabrics. A comparison of Tables 6 and 7 suggests that at least three layers of each

13 reinforcing fabric should be used in the 10 - $\mathrm{mm}$ thick ferrocement sheet in order to exceed the

14 minimum reinforcement ratio.

16 Figure 10 presents typical load-deflection and stress-strain curves for the 10-mm thick

17 ferrocement specimen with three layers of 'Jute 2' burlap reinforcement; this specimen exhibited

18 multiple cracking. The load-deflection curve for this specimen provided a strain-hardening

19 behavior followed by a plateau that corresponds to development of multiple cracks after

20 formation of the first crack. As expected, failure eventually occurs by growth of one of the

21 cracks. Individual 'Jute 1' burlaps with a width similar to that of ferrocement specimens

22 provided about $300 \mathrm{~N}$ peak load. While the major trend towards nonlinear behavior in Figure 10

23 (left) started at about 1,000 N (3 times the tensile load-carrying capacity of individual fabrics, 
1 noting that the ferrocement specimen has three 'Jute 2' fabric layers), the strain-hardening

2 behavior of ferrocement almost doubled this load at peak. One may hypothesize that the

3 supporting role of matrix (e.g., for redistributing stresses away from critically stressed yarns and

4 regions of fabric, confinement of woven fabrics against realignment which could induce a

5 composite behavior, and filling of the pores within yarns with cement hydrates) could enhance

6 the fabric tensile strength in ferrocement versus the tensile strength of bare fabric. Although tests

7 were conducted at a young age of 7 days, there were indirect indications of filling of yarn pores

8 with cement hydrates; the yarn segments that pulled out of mortar seemed to be stiffer than the

9 as-received yarn.

10 The reinforcement volume fractions of the 10-mm thick ferrocement sheets with different

11 reinforcement systems were very close to their theoretical minimum values (see Tables 6 and 7).

12 Therefore, these ferrocement sheets may or may not exhibit multiple cracking. The ferrocement

13 sheet with three layers of chicken mesh did not experience multiple cracking. Chicken mesh was

14 found to be sensitive to the stress concentration generated at end grips; the single crack which

15 was responsible for failure of ferrocement specimens with chicken mesh reinforcement occurred

16 near the end grip. This was not the case with the 'Jute 2' burlap reinforcement which seemed to

17 provide a desired toughening effect and the ability to mitigate localization of damage at the

18 highly-stressed regions.

19 In the case of the 'Jute 1' burlap with $1.5 \mathrm{~mm}$ opening between yarns, considering that the sand

20 used in the mortar matrix had a maximum particle size of $1.5 \mathrm{~mm}$, failure occurred by

21 delamination of the mortar coating on the outer layer of burlap while some tendencies towards

22 multiple cracking were also observed. This observation indicates that the maximum particle size

23 of sand in mortar should be smaller than the fabric opening size. Reduction of the ferrocement 
1 sheet size to $10 \mathrm{~mm}$ pronounced the adverse filtering effect of the 'Jute 1' burlap with fine

2 opening size against coarser sand particles. In this case, even with two 'Jute 1' burlaps, a brittle

3 failure mode was observed with a peak load that was smaller than twice the tensile load-bearing

4 capacity of a single 'Jute 1' burlap tested in tension.

$<$ Table 10>

\section{$6 \quad 3.3$ Evaluation of the sandwich composite behavior in flexure}

7 Figure 11 presents the setup for flexure testing of the sandwich composite specimen. This

8 ferrocement skin with two layers of 'Jute 2' burlap provides a peak tensile force of about 1,000

$9 \mathrm{~N}$, obtained in tension testing of a 10-mm thick ferrocement sheet with similar reinforcement condition. With $100 \mathrm{~mm}$ center-to-center spacing of the upper and lower skins, the ultimate

11 flexural strength of the sandwich composite, when failure is governed by tensile rupture of the

12 lower (tensile) skin, would be 1,000x 100=100,000 N.mm. In a four-point flexure test over a span

13 of $250 \mathrm{~mm}$, this flexural strength translates into $6 \times 100,000 / 250=2,400 \mathrm{~N}$ peak load.

14 Under increasing flexural loading, initial cracking occurred in the aerated concrete core, starting

15 just above the lower skin, which prompted cracking of the ferrocement skin. Subsequently, with

16 further increase in load, the tensile crack in lower skin grew, and failure occurred by full-depth

17 cracking of the sandwich composite at the section where core cracking initiated. Failure occurred

18 by the growth of the initial crack, without any indication of multiple cracking. Full-depth

19 cracking of the composite specimen indicates that delamination of skins led to the loss of

20 sandwich composite behavior, with each skin acting independently in flexure. If the sandwich

21 composite behavior would have continued without skin delamination, ultimate failure could have

22 induced crushing of the top skin in compression. 
1 The flexural load-deflection behavior of this sandwich composite specimen (Figure 11) indicates

2 that the experimentally obtained peak load $(\sim 4,400 \mathrm{~N})$ is significantly higher than the

3 theoretically predicted value of 2,400 N. This theoretical calculation considered moment to be

4 equal to the tensile strength of skin (derived based on experimental results) times the center-to-

5 center distance of the two skins. It neglected the contribution of the core to flexural strength, and

6 the change in skin behavior from axial to flexural. The failure mode of this sandwich composite

7 specimen under monotonic loading could be characterized as ductile. After removal of the failed

8 sandwich composite specimen from the test machine, it was noted that the tension skin was fully

9 debonded from the core. The aerated concrete core used in this sandwich composite was of

10 relatively high density and strength; it is thus expected to raise the flexural strength of the

11 sandwich composite. Initiation of failure by tensile cracking of the aerated concrete core implies

12 that the tensile strain capacity of the core was not adequate, which could be attributed to the

13 relatively high density of this aerated concrete. Delamination of the tensile skin from the core

14 and initial cracking of the core indicate that the structural behavior of the sandwich composite

15 would benefit from improved interfacial stress transfer and increased strain capacity of the core.

$<$ Figure 11>

17

$<$ Figure 12>

\section{Conclusions}

- Natural fabric (burlap) and chicken mesh are viable (indigenous) reinforcement systems for production of ferrocement, which was produced in this research with an indigenous binder

21 developed in the project. The high reinforcement ratio and specific surface area, and the

22 improved bonding via mechanical anchorage of the 2D fabric reinforcement induced multiple 
cracking in ferrocement under tensile and flexural loading. This phenomenon enables redistribution of force from critically stressed regions, and enhances the ductility and energy absorption capacity of ferrocement structures.

- The concept of minimum reinforcement ratio for inducing ductile modes of failure and multiple cracking was verified. Adequate reinforcement ratios were found to induce strainhardening type of behavior. The ultimate tensile load-bearing capacity of ferrocement was found to exceed that of its constituent reinforcement. This was attributed to the stress redistribution capabilities (after local fiber/yarn rupture) provided by the cementitious matrix, precipitation of hydrates within yarn pores (which raises their strength), and the governing role of cementitious matrix in determining the location of failure which is probably away from the weakest link(s) within the reinforcing fabric. Tension test results also indicated that jute burlaps can produce ferrocement sheets with structural qualities (strength, stiffness, ductility) which match those offered by chicken mesh (steel fabric) reinforcement.

- Studies were conducted on indigenous sandwich composites comprising ferrocement skins with jute burlap reinforcement and an aerated concrete core made of lime-gypsum matrix and (natural) saponin foaming agent. The aerated concrete used here was of relatively high density. Flexure tests of this sandwich composite produced failure modes which pointed at the contributions of the relatively dense aerated concrete core to flexural performance. Lighter cores with relatively large strain capacity as well as improved bonding of ferrocement skins to the aerated concrete core would be required for realizing failure modes which ensure effective use of the ferrocement skin strength and ductility towards achieving a desired balance of flexural strength, ductility and toughness in lightweight sandwich composites. 
Acknowledgment

The authors wish to acknowledge the support of Department of Defense (DOD) U.S. Army

(Grant No. W9132T-15-C-0002) for the study reported herein.

\section{References}

1. Graham, P., Building ecology: First principles for a sustainable built environment. 2009: John Wiley \& Sons.

2. Kuchena, J. and P. Usiri, Low cost construction technologies and materials-case study Mozambuique. 2009.

3. Joseph, P. and S. Tretsiakova-McNally, Sustainable non-metallic building materials. Sustainability, 2010. 2(2): p. 400-427.

4. Allen, E. and J. Iano, Fundamentals of building construction: materials and methods. 2011: John Wiley \& Sons.

5. Matalkah, F., et al., Use of non-wood biomass combustion ash in development of alkaliactivated concrete. Construction and Building Materials, 2016. 121: p. 491-500.

6. Reddy, B.V. and K. Jagadish, Embodied energy of common and alternative building materials and technologies. Energy and buildings, 2003. 35(2): p. 129-137.

7. Mehta, P.K. and R.W. Burrows, Building durable structures in the 21 st century. Indian Concrete Journal, 2001. 75(7): p. 437-443.

8. Silveira, D., H. Varum, and A. Costa, Influence of the testing procedures in the mechanical characterization of adobe bricks. Construction and Building Materials, 2013. 40: p. 719-728.

9. Billong, N., et al., Properties of compressed lateritic soil stabilized with a burnt clay-lime binder: Effect of mixture components. Construction and Building Materials, 2009. 23(6): p. 2457-2460.

10. Bui, Q., et al., Durability of rammed earth walls exposed for 20 years to natural weathering. Building and Environment, 2009. 44(5): p. 912-919.

11. Sukmak, P., et al., Factors influencing strength development in clay-fly ash geopolymer. Construction and Building Materials, 2013. 47: p. 1125-1136.

12. Gamrani, N., et al., The particular "rammed earth" of the Saadian sugar refinery of Chichaoua (XVIth century, Morocco): mineralogical, chemical and mechanical characteristics. Environmental Earth Sciences, 2012. 66(1): p. 129-140.

13. Greepala, V. and P. Nimityongskul, Structural integrity of ferrocement panels exposed to fire. Cement \& Concrete Composites, 2008. 30(5): p. 419-430.

14. Wafa, M.A. and K. Fukuzawa, Characteristics of ferrocement thin composite elements using various reinforcement meshes in flexure. Journal of Reinforced Plastics and Composites, 2010. 29(23): p. 3530-3539. 
15. Alomayri, T., F.U.A. Shaikh, and I.M. Low, Effect of fabric orientation on mechanical properties of cotton fabric reinforced geopolymer composites. Materials and Design, 2014. 57: p. 360-365.

16. Shannag, M.J. and T. Bin Ziyyad, Flexural response of ferrocement with fibrous cementitious matrices. Construction and Building Materials, 2007. 21(6): p. 1198-1205.

17. Matalkah, F., et al., Characterization of Alkali-Activated Nonwood Biomass Ash-Based Geopolymer Concrete. Journal of Materials in Civil Engineering, 2016: p. 04016270.

18. Kahn, M.E., The death toll from natural disasters: the role of income, geography, and institutions. Review of Economics and Statistics, 2005. 87(2): p. 271-284.

19. Yao, W. and Z. Li, Flexural behavior of bamboo-fiber-reinforced mortar laminates. Cement and concrete research, 2003. 33(1): p. 15-19.

20. Ribeiro, B., D. Barreto, and M. Coelho, Application of foam column as green technology for concentration of saponins from sisal (Agave sisalana) and Juá (Ziziphus joazeiro). Brazilian Journal of Chemical Engineering, 2013. 30(4): p. 701-709.

21. Matalkah, F., et al., Development and Characterization of Gypsum-Based Binder. European Journal of Advances in Engineering and Technology, 2017. 4(3): p. 153-157.

22. Sen, T. and H.J. Reddy, Various industrial applications of hemp, kinaf, flax and ramie natural fibres. International Journal of Innovation, Management and Technology, 2011. 2(3): p. 192.

23. Yan, L., N. Chouw, and K. Jayaraman, Flax fibre and its composites-a review. Composites Part B: Engineering, 2014. 56: p. 296-317.

24. Thomas, S., et al., Natural fibres: Structure, properties and applications, in Cellulose Fibers: Bio-and Nano-Polymer Composites. 2011, Springer. p. 3-42.

25. Nădăşan, L. and T. Oneţ, POSSIBLE USE OF FERROCEMENT IN ROMANIA. Bulletin of the Polytechnic Institute of Iasi-Construction \& Architecture Section, 2013. 63(2).

26. Naaman, A.E., Ferrocement and laminated cementitious composites. Vol. 3000. 2000: Techno press.

27. Mattone, R., Ferrocement in low cost housing: an application proposal. use of ferrocement in rural housing projects. Journal of ferrocement, 1992. 22(2): p. 181-187.

28. Satyanarayana, K.G., et al., Natural fibre-polymer composites. Cement \& Concrete Composites, 1990. 12(2): p. 117-136.

29. Golemanov, K., et al., Remarkably high surface visco-elasticity of adsorption layers of triterpenoid saponins. Soft Matter, 2013. 9(24): p. 5738-5752.

30. Hamad, A.J., Materials, Production, Properties and Application of Aerated Lightweight Concrete: Review. 2014.

31. Zini, E. and M. Scandola, Green composites: An overview. Polymer Composites, 2011. 32(12): p. 1905-1915. 
Table 1. Mix designs of aerated concrete.

\begin{tabular}{cccc}
\hline Binder composition & Binder & Foaming agent & Water \\
\hline 0.20 Lime: 0.80 Gypsum & 1.0 & 0.002 & 0.6 \\
\hline
\end{tabular}


Table 2. Compressive strength and density test results for aerated concrete.

\begin{tabular}{cc}
\hline 7-Day compressive strength, $\mathrm{MPa}$ & Density, $\mathrm{g} / \mathrm{cm}^{3}$ \\
\hline 3.65 & 0.91 \\
\hline
\end{tabular}


Table 3. Mean values of the mechanical properties of jute yarns. Tensile Strength, MPa Strain at Failure, \% $\quad$ Elastic Modulus, GPa

$\begin{array}{lll}108 & 7.10 & 3.20\end{array}$


Table 4. Mean values of the mechanical properties of jute burlaps and chicken mesh.

\begin{tabular}{ccccc}
\hline Fabric & $\begin{array}{c}\text { Cross-sectional area } \\
\text { (solid) }, \mathrm{mm}^{2}\end{array}$ & $\begin{array}{c}\text { Tensile } \\
\text { strength }^{*}(\mathrm{MPa})\end{array}$ & $\begin{array}{c}\text { Strain at } \\
\text { failure (\%) }\end{array}$ & $\begin{array}{c}\text { Elastic } \\
\text { modulus (MPa) }\end{array}$ \\
\hline $\begin{array}{c}\text { Chicken } \\
\text { mesh }\end{array}$ & 10.05 & 85.0 & 0.22 & 4000 \\
\hline $\begin{array}{c}\text { 'Jute 1' } \\
\text { burlap }\end{array}$ & 39.33 & 22.6 & 0.03 & 818 \\
\hline $\begin{array}{c}\text { 'Jute 2' } \\
\text { burlap }\end{array}$ & 12.46 & 25.1 & 0.09 & 800
\end{tabular}

* Nominal stress points at the misalignment of wires in chicken mesh with respect to the tensile loading direction 
Table 5. Calculation of reinforcement ratios for 20 -mm thick ferrocement sheets with 1 or 2 layers of different reinforcing fabrics.

\begin{tabular}{ccccccc}
\hline Reinforcement Type & $\mathrm{d}_{w}(\mathrm{~mm})$ & $\mathrm{D}_{T}(\mathrm{~mm})$ & $\mathrm{D}_{L}(\mathrm{~mm})$ & $\mathrm{N}$ & $\mathrm{h}(\mathrm{mm})$ & $\mathrm{V}_{r}$ \\
\hline Chicken mesh & 1.60 & 20.0 & 60.0 & 2.0 & 20.0 & 0.01 \\
\hline Chicken mesh & 1.60 & 20.0 & 60.0 & 1.0 & 20.0 & 0.01 \\
\hline Jute 1 & 1.20 & 1.50 & 1.50 & 2.0 & 20.0 & 0.15 \\
\hline Jute 1 & 1.20 & 1.50 & 1.50 & 1.0 & 20.0 & 0.08 \\
\hline Jute 2 & 0.90 & 3.0 & 3.00 & 2.0 & 20.0 & 0.04 \\
\hline Jute 2 & 0.90 & 3.0 & 3.00 & 1.0 & 20.0 & 0.02
\end{tabular}


Table 6. Calculation of minimum reinforcement ratios for different reinforcing fabrics.

\begin{tabular}{ccccc}
\hline Mesh & $\sigma_{\mu v}$ & $\sigma_{\rho v}$ & $\mathrm{n}$ & $\left(\mathrm{V}_{r}\right)_{\min }$ \\
\hline Chicken mesh & 2.40 & 85.0 & 10.0 & 0.04 \\
\hline Jute 1 & 2.40 & 22.6 & 8.0 & 0.42 \\
\hline Jute 2 & 2.40 & 25.1 & 3.0 & 0.14 \\
\hline
\end{tabular}




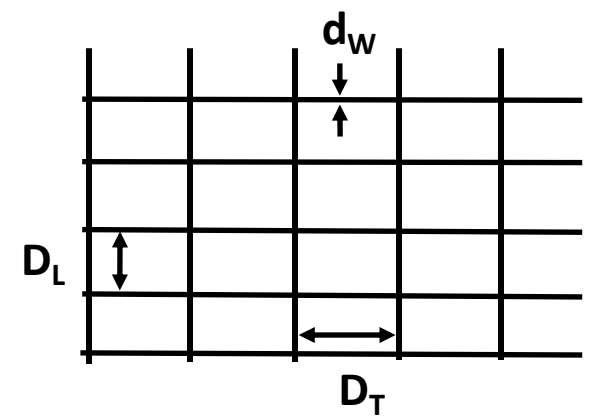

Figure 1. Geometric attributes of fabric reinforcement. 

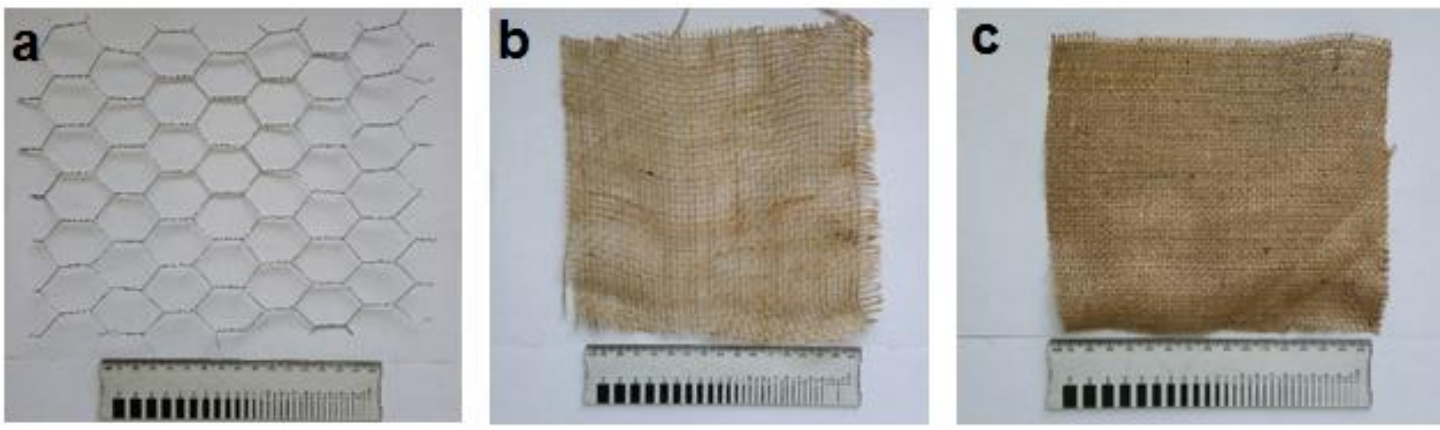

Figure 2. The jute burlaps and the chicken mesh selected for use in this study, (a) chicken mesh; (b) jute 1 and (c) is jute 2 

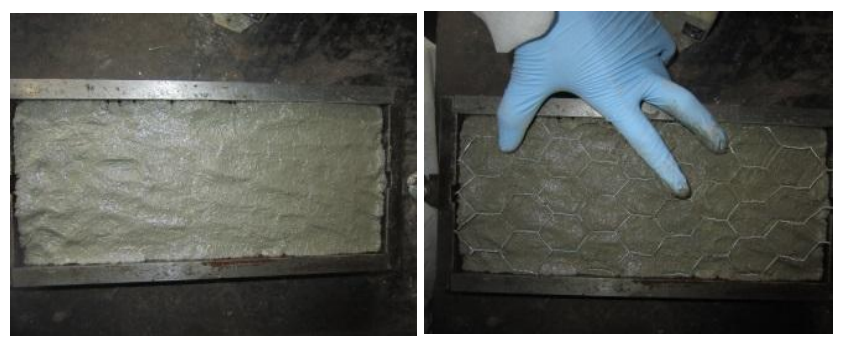

(a) Mortar layer

(b) Chicken mesh

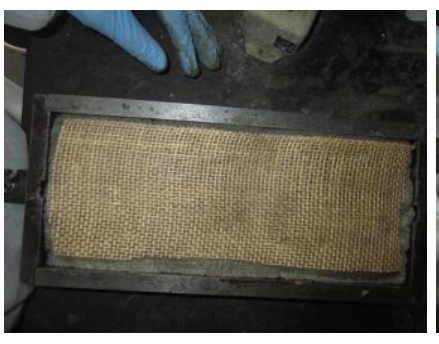

(c) Jute 1

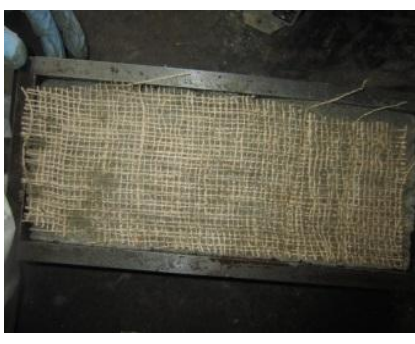

(d) Jute 2

Figure 3. Preparation of ferrocement specimens. 


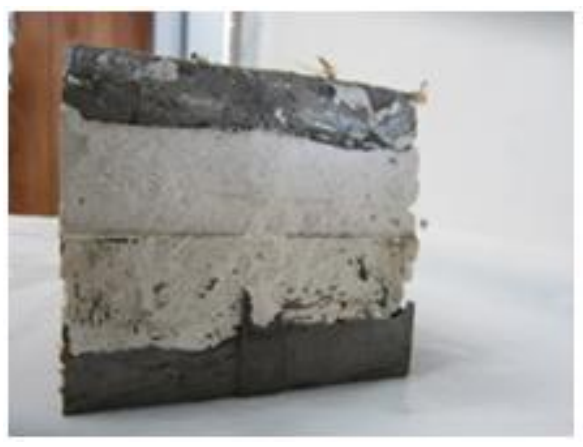

(a) Cross section

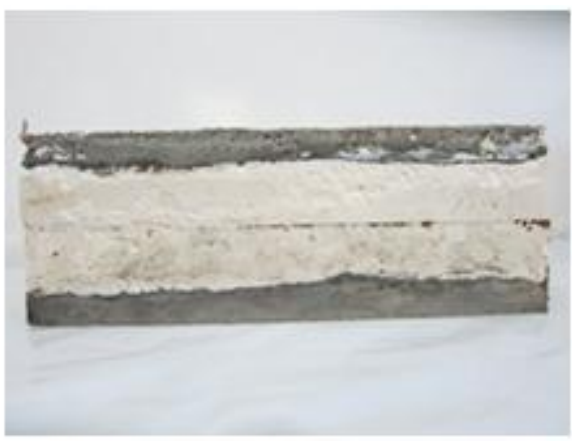

(b) Side view

Figure 4. The cross section and side view of the sandwich composite specimen 


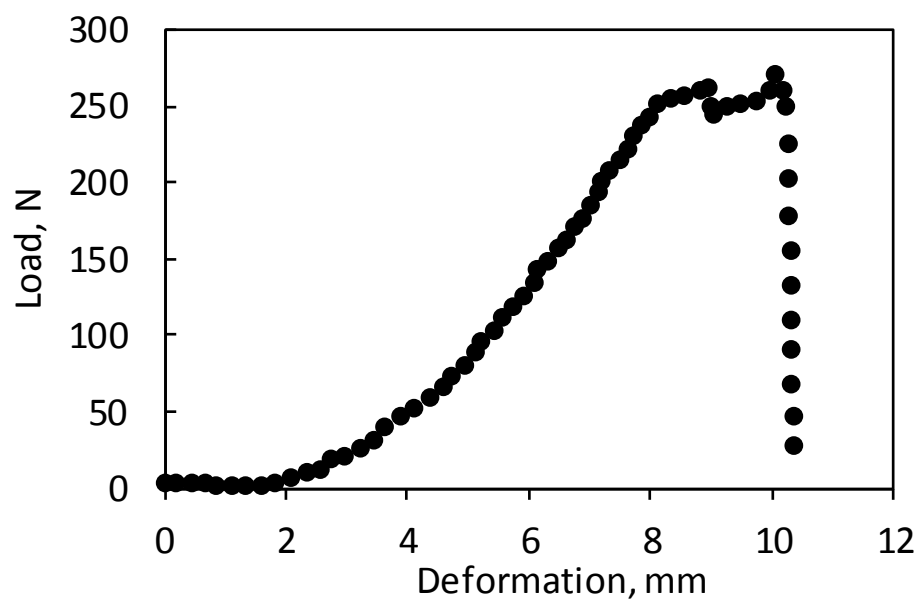

Figure 5. Typical tensile load-deformation behavior of jute fiber yarns. 


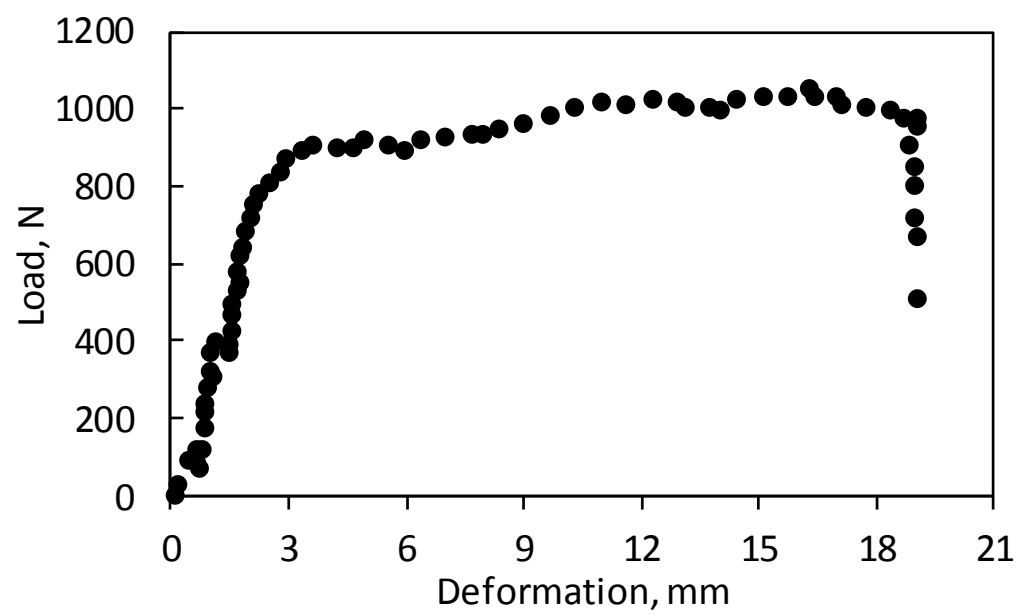

Figure 6. Typical tensile load-deformation behavior of chicken mesh. 


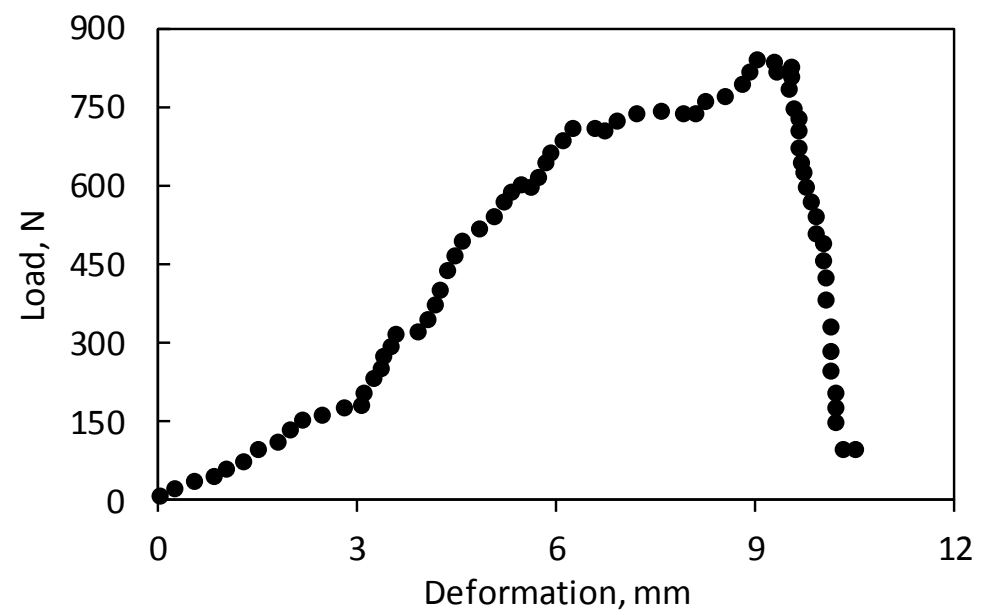

Figure 7. Typical tensile load-deformation behavior of the 'Jute 1' burlap. 


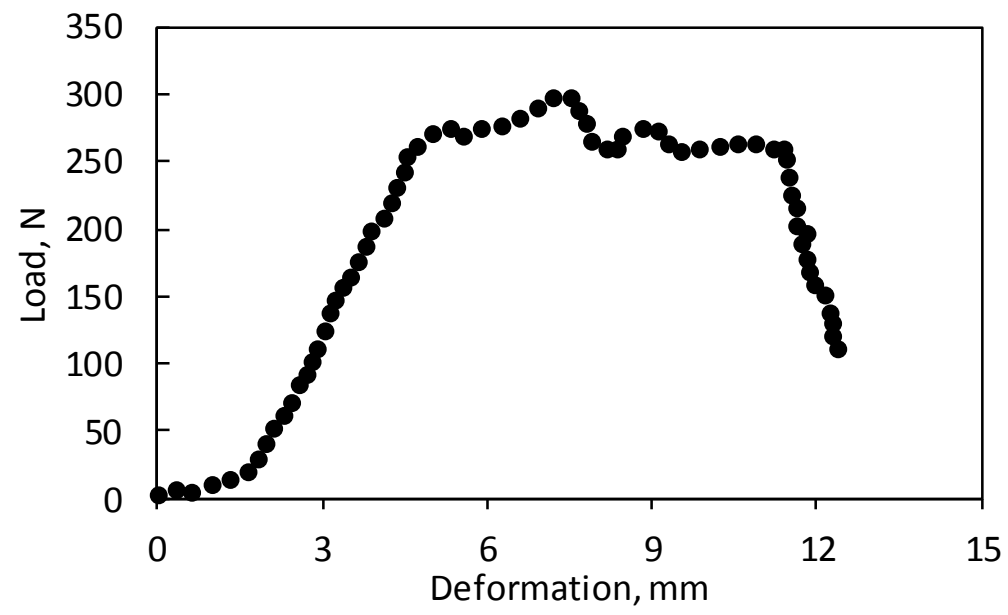

Figure 8. Typical tensile load-deformation behavior of the 'Jute 2' burlap 


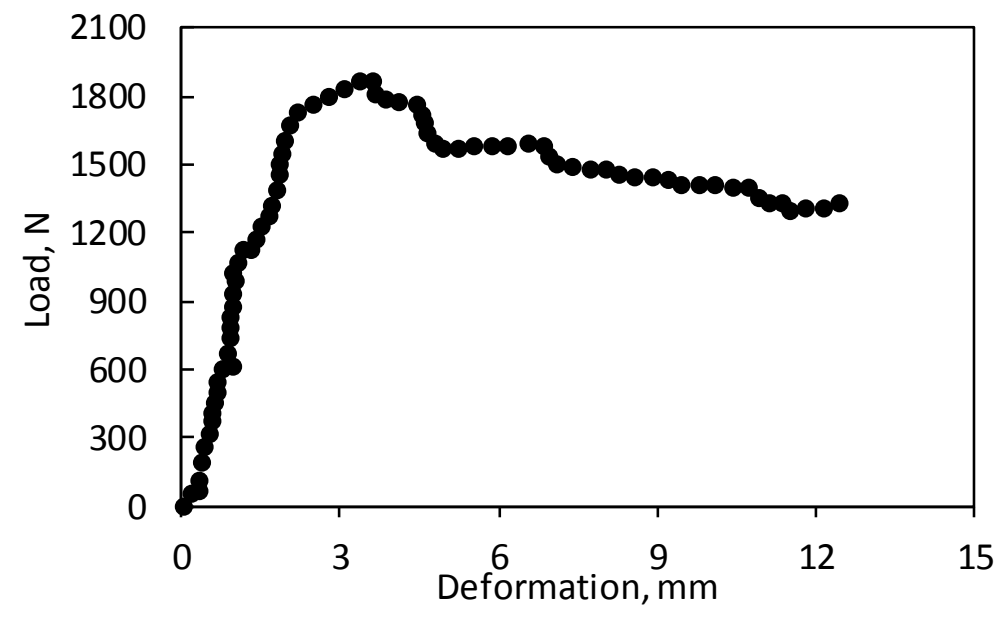

Figure 9. Typical tensile load-deformation curve of ferrocement sheets with 20-mm thickness and 2 layers of chicken mesh. 


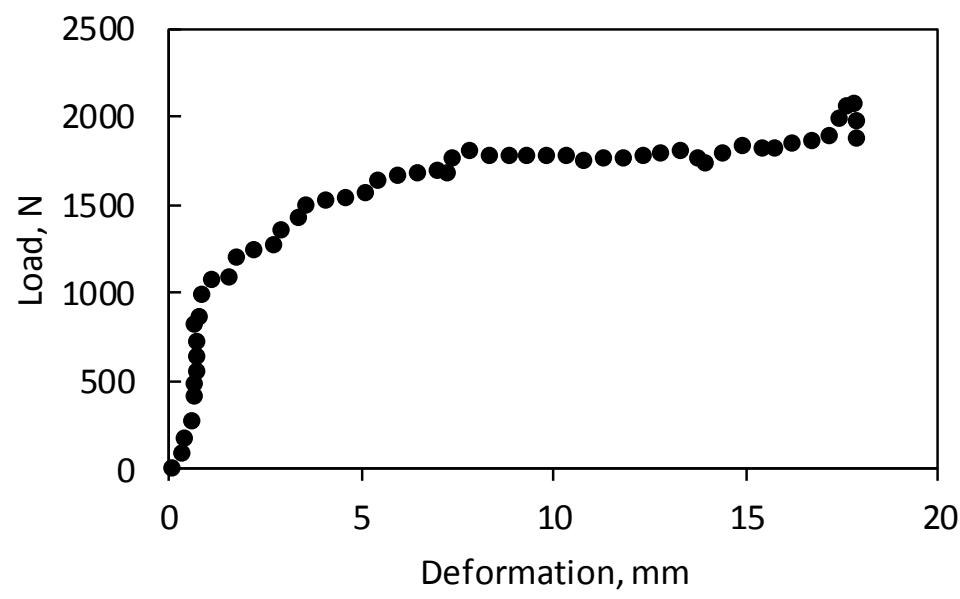

Figure 10. Tensile load-deformation curve for 10-mm thick ferrocement specimen reinforced with 3 layers of 'Jute 2' burlap. 


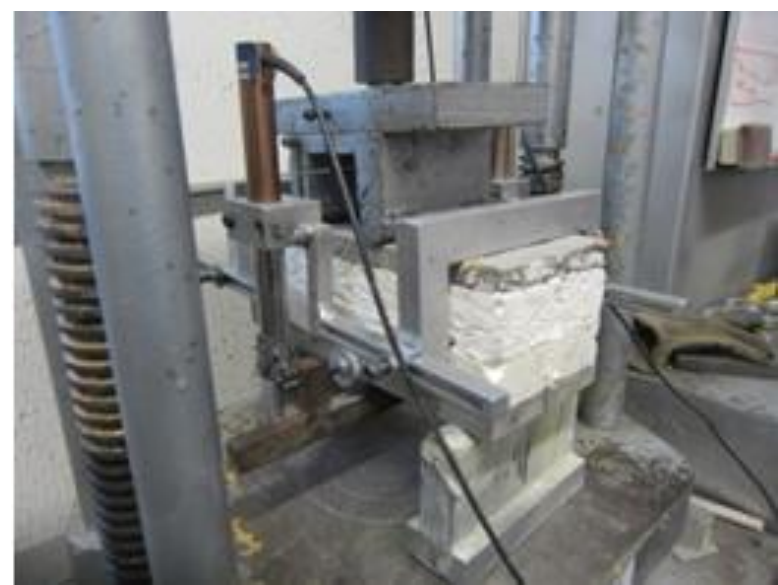

Figure 11. Sandwich composite flexure test setup. 


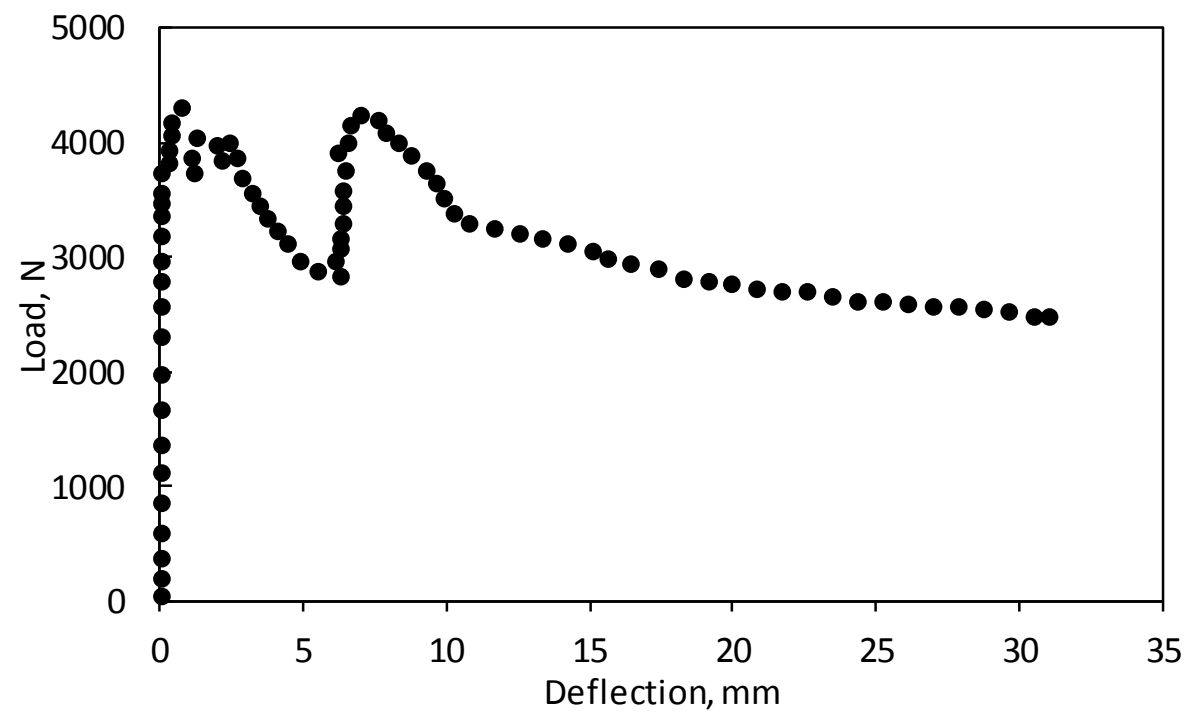

Figure 12. Flexural load-deflection behavior of the sandwich composite. 